\title{
An Original Method for Making an Immediate Post Extraction Temporary Anterior Bridge in a Single Visit: A Case Report
}

\author{
Saafi J*, Al-ojaym T, Hussain A, Al-amri S, Gasmi I and Cherif M \\ Faculty of Dental Medicine, University of Monastir, Tunisia
}

*Corresponding author: Saafi Jilani, Faculty of Dental Medicine, University of Monastir, Tunisia,Email: saafi_jilani@yahoo.fr

\section{Case Report \\ Volume 3 Issue 1}

Received Date: February 28, 2018

Published Date: March 19, 2018

DOI: $10.23880 /$ oajds-16000168

\section{Abstract}

A Patient, with a poor prognosis of mandibular incisor mobility, requires an extended treatment sequence that involves extractions and will generally want esthetic and functional prosthesis at the earliest possible opportunity. This paper describes immediate replacement of two mandibular incisors by an interim bridge in a single visit using an immediate acryl bridge.

Keywords: Direct technique; Bridge; Resin acryl; Extraction

\section{Introduction}

The main causes of missing of anterior teeth are trauma and periodontal disease. The removal with no replacing of anterior teeth can be psychologically and socially damaging to the patient. A wide range of treatment options available, these include a removable temporary acrylic prosthesis, resin-bonded bridges, Fiber-Reinforced Composite (FRC) bridges, immediate loaded implant supported prosthesis and immediate temporarily acryl bridge [1]. Cosmetic demands, functional needs, treatment sequencing, timeliness, and affordability are some primary concerns that must be addressed on an individual basis [2].

Provisional anterior bridge must satisfy many requirement such as pulp protection, maintain periodontal health, tooth position, Protection against fracture ,resistance to functional loads ,resistance to removal forces maintain interabutment alignment and esthetic [3]. It serves the critical function of providing a template for the final restorations once it has been evaluated intraorally [4]. In certain degrees of teeth mobility interim bridge ensures positional stability and can be used to splint teeth against mobility for further prognosis assessment.

\section{Case Presentation}

A 30-year healthy female patient presented to the department of fixed prosthodontics at the dental clinic of Monastir (Tunisia). She complained about mobility of anterior mandibular cantilever resin veneered bridge and asked for an aesthetic, pleasing and natural like life smile. She also requested a functional restoration during mastication and phonation. Dental history did not reveal any past present symptom. The mobility of the central incisors was related to a periodontal disease and trauma of overloading. Intra-oral examination showed a severe mobility (degree 3 ) of mandibular right central incisor as abutment of a cantilever bridge (Figure 1) replacing the left central incisor with significant bone loss revealed by periapical X-Ray (Figure 2). 

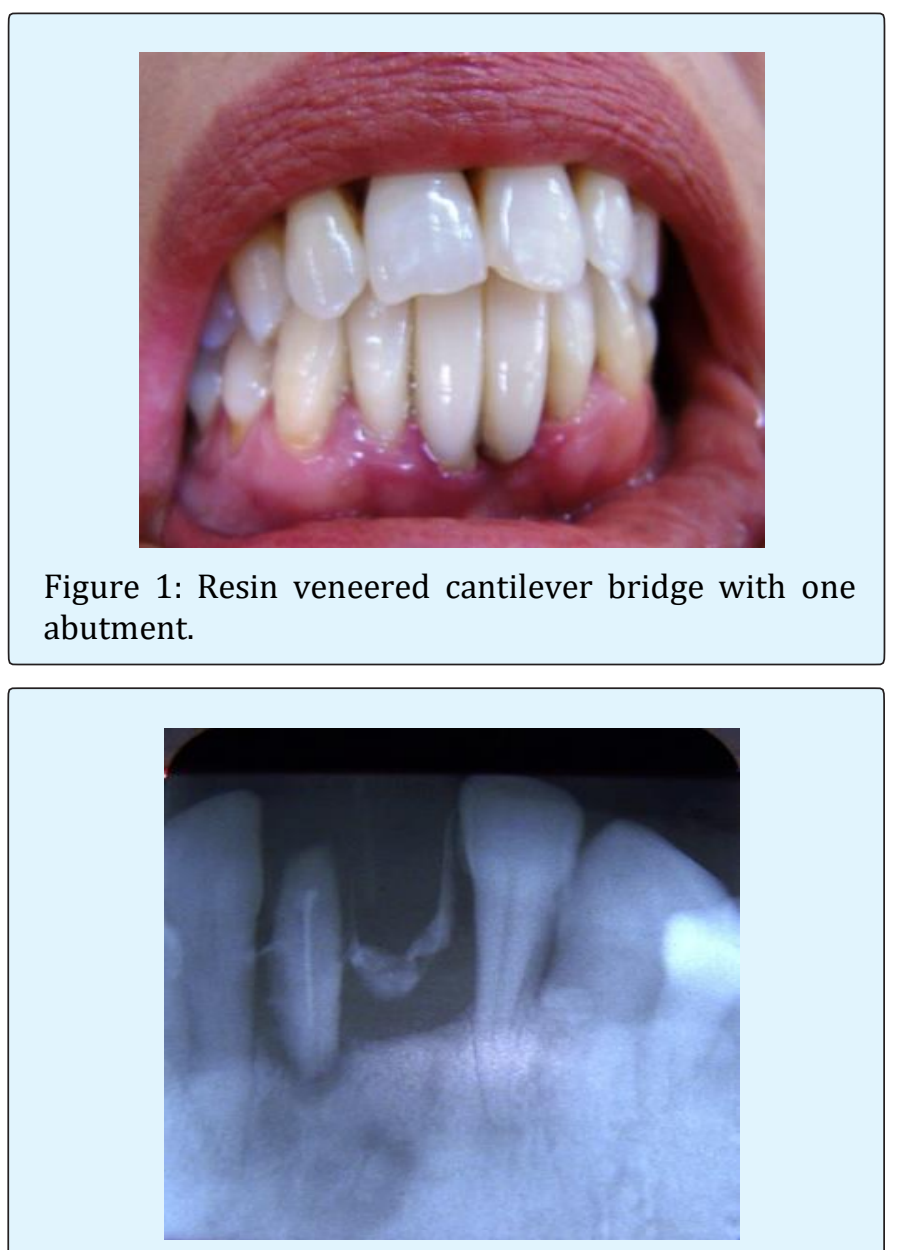

Figure 2: Severe bone loss jeopardizing the prognosis of central incisor.
The anterior guide is non functional with posterior interferences.

To ascertain function and esthetics, the treatment protocol is an immediate treatment including interim restorative approaches after removal of the cantilever bridge involving the central right incisor. The patient was not willing to wear a removable appliance; a fixed interim alternative provisional bridge was indicated as immediate post extractive temporary bridge [5].

The suitable abutments are canines and lateral incisors. The theories and techniques of fabrication for numerous types of provisional restorations abound in the dental literature [6]. There are many techniques to perform provisional bridges:

a) Indirect Provisional Fixed Partial Denture

b) Indirect-Direct Provisional Fixed Partial Denture

c) Direct Provisional Fixed Partial Denture [7]

\section{Procedure}

In the direct technique, patient's prepared teeth and the gingival tissues directly provide the tissue surface form eliminating all the intermediate laboratory procedures.

a) Before the tooth preparation, make silicone putty impression using a tray (putty index like) (Figures 3 \& 4).

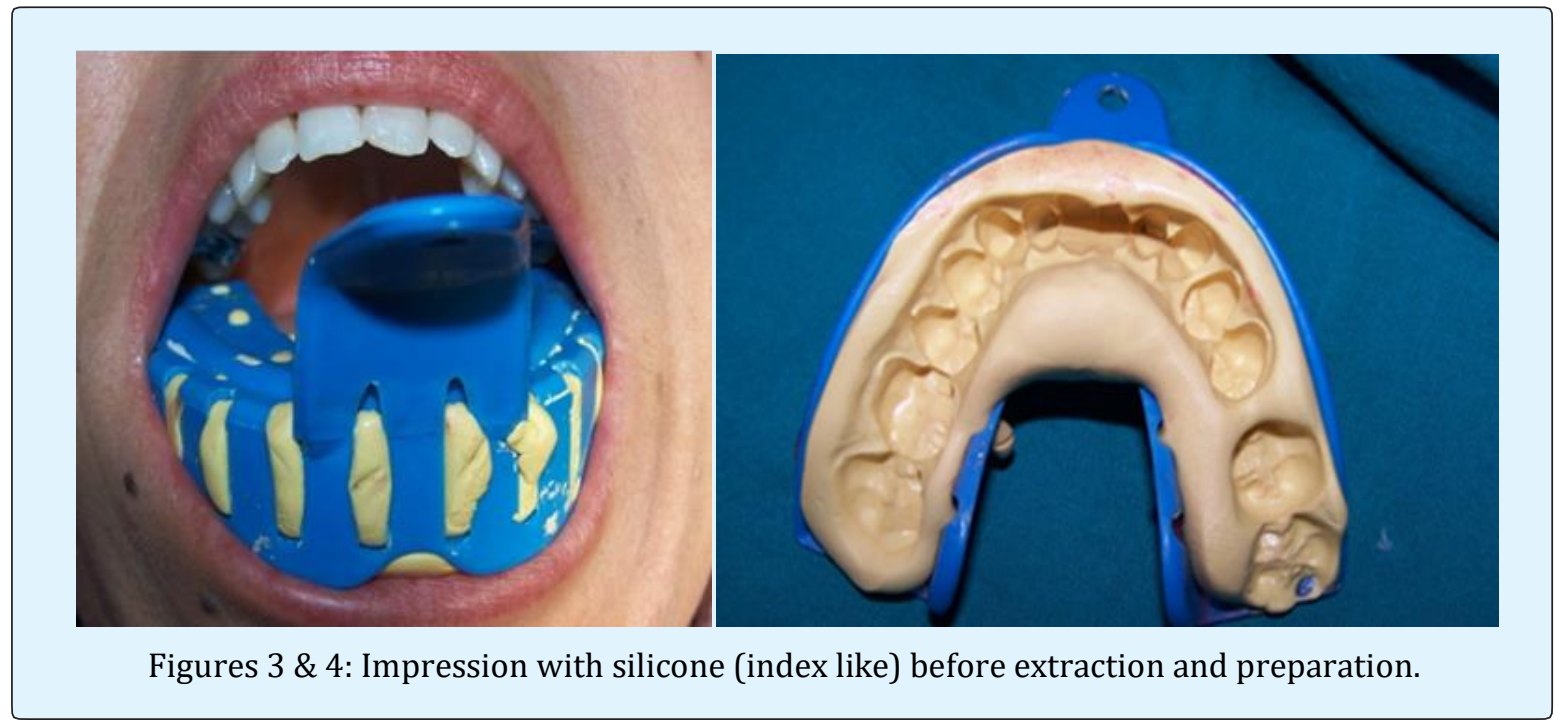

Saafi J, et al. An Original Method for Making an Immediate Post Extraction Temporary Anterior Bridge in a Single Visit: A Case Report. J Dental Sci 2018, 3(1): 000168. 
After shade selection Prepare the patient's canines and incisors as abutments for the anterior bridge in the usual manner and care must be taken for the path of placement of the restoration (Figure 5).

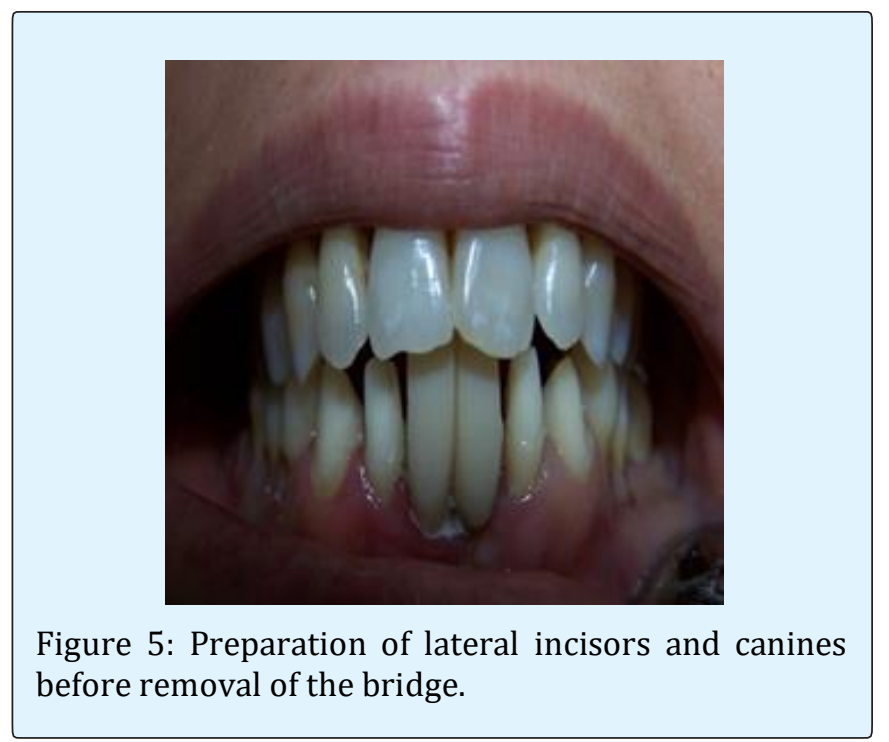

After protecting the prepared vital teeth with varnish, the patient was referred to the department of oral surgery in order to extract simultaneously the tooth with the bridge (Figure 5). Sutures were performed to stop beading and to hasten and ease healing.

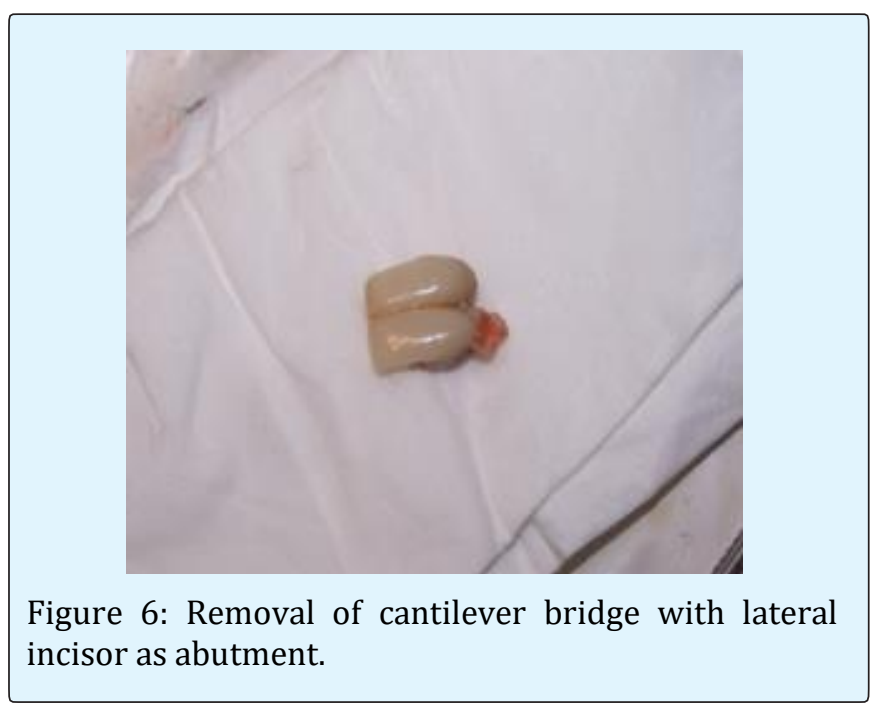

a) Lubricate the prepared teeth and the adjacent teeth with Vaseline,

b) Prepare resin acryl (e.i., Dentalon plus) (figures 7 and 8 ) and load it into the impression.

The impression should not overfilled; the resin should just reach the level of the gingival [3].

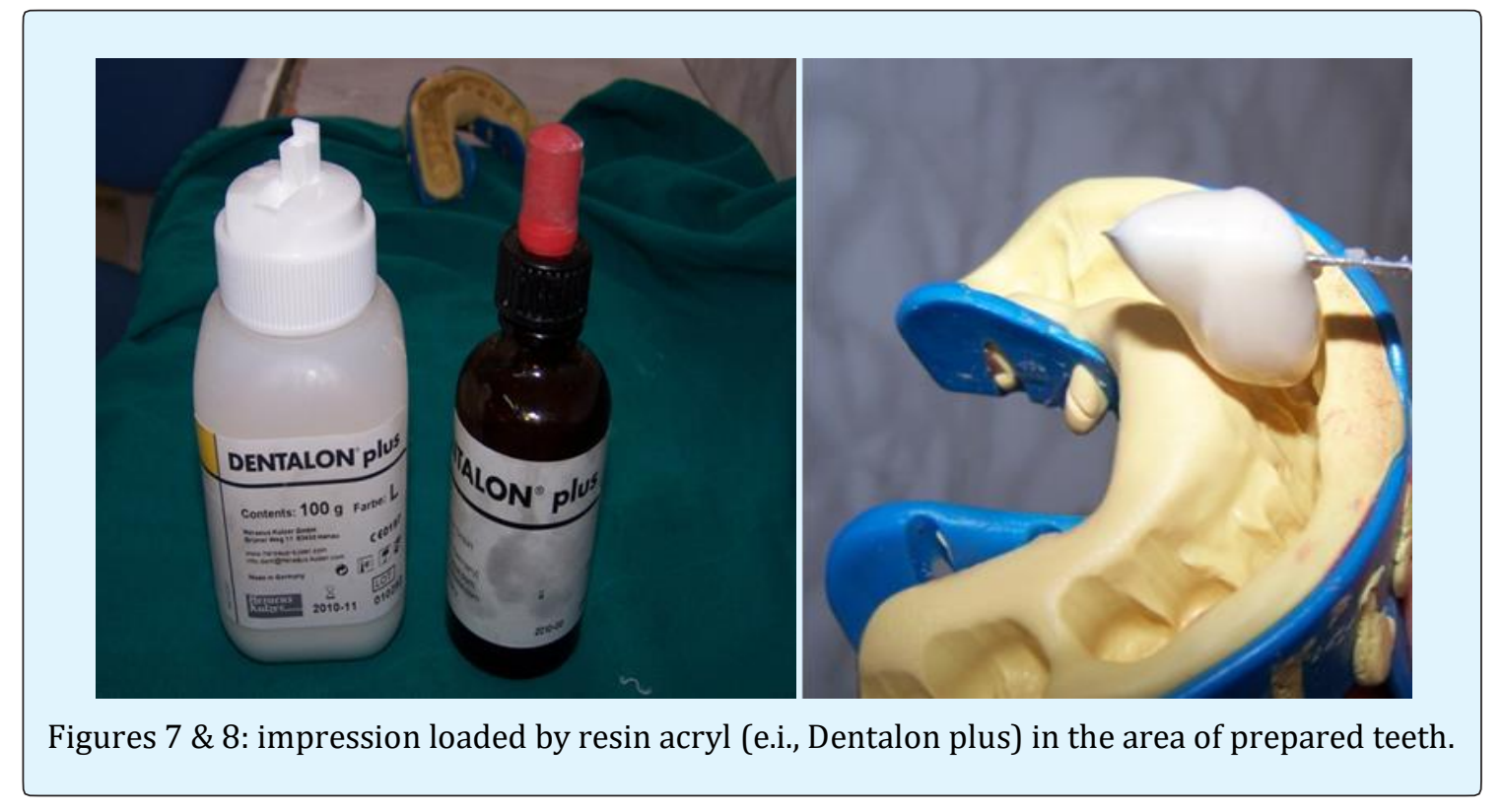

- Reseat the silicone impression with provisional restorative material in the mouth of patient. 


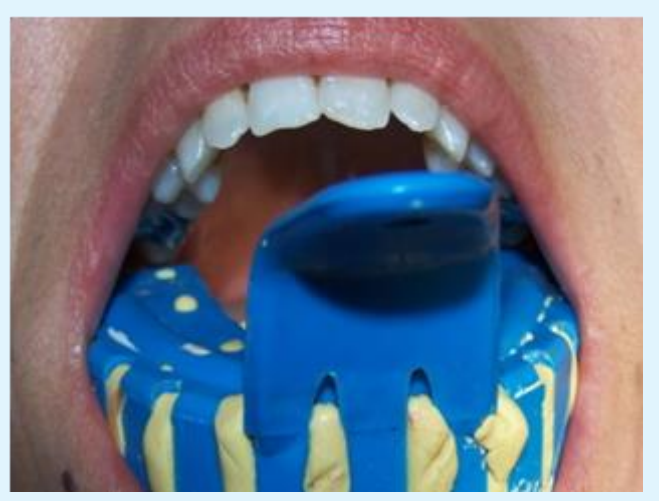

Figure 9: Silicone impression loaded by acryl inserted in the mouth.

a) Remove and reseat the restoration until it sets.

b) Trim, finish, polish, and cement the bridge (Figure 10)

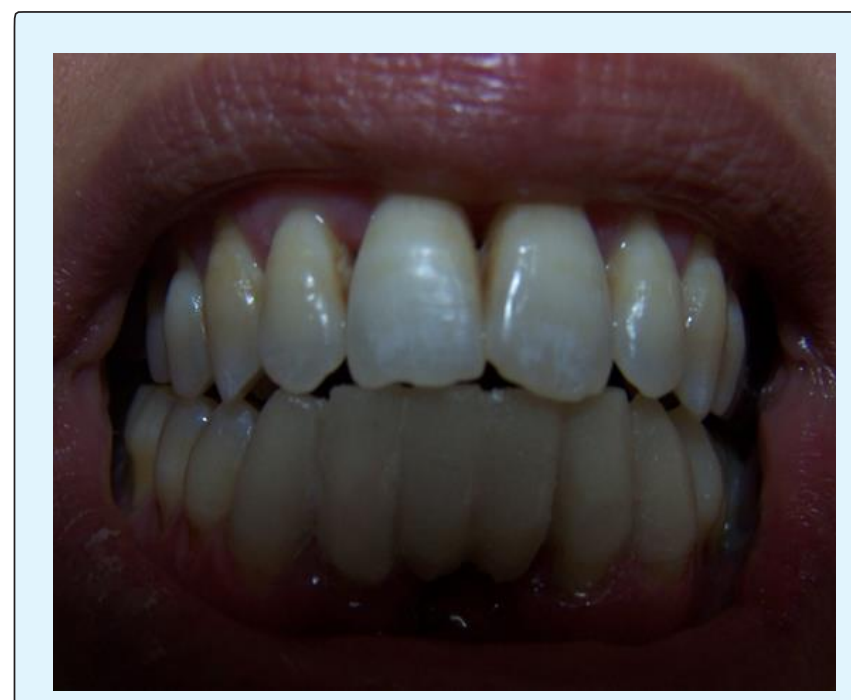

Figure 10: Immediate interim bridge cemented, with acceptable esthetic result.

\section{Discussion}

This article described one case with an immediate replacement of the mandibular incisor teeth. In this clinic case and according to Ant's law the replacement of two incisors using four abutments; lateral incisors and canines was a suitable solution [8]. Tooth mobility occurs when bony support is lacking. It is not necessarily a sign of disease, because it may be a normal response to abnormal forces, and it does not always need corrective treatment. Depending on the patient's need, the teeth were treated by splinting with provisional restoration [3]. Interim fixed prostheses were used in periodontally compromised teeth with poor prognosis and can also be retained for a longer time by using splints until a definitive treatment plan was made. It Restored esthetics and occlusal scheme to incorporate a definitive prosthesis in future and it provided time for evaluation of design and occlusal form before deciding to proceed with definitive restoration $[9,10]$. This method is a conservative, rapid, and functional as an interim restoration after the removal of the cantilever bridge to provide immediate esthetic [11]. The procedure was completed at the chair side, and costeffective avoiding the laboratory costs. Nevertheless, this immediate post extraction method has significant inconveniences like potential tissue trauma from the polymerizing resin, because a directly made interim restoration with large pontic is more likely to cause injury to the pulp, and inherently poorer marginal fit due to removing temporary bridge before becoming rigid [3].

\section{Conclusion}

Immediate replacement of missing anterior teeth is a real challenge. A rapid technique can be used for placement an immediate temporary bridge to provide immediate esthetics and function after extraction of mandibular anterior tooth.

\section{References}

1. Khetarpal A, Talwar S, Verma M (2013) Creating a Single-Visit, Fibre-Reinforced, Composite Resin Bridge by Using a Natural Tooth Pontic: A Viable Alternative to a PFM Bridge. J Clin Diagn Res 7(4): 772-775.

2. Hannon SM, Breault LG, Kim AC (1998) The immediate provisional restoration: a review of clinical techniques. Quintessence Int 29(3): 163-169.

3. Stephen R, Land M, Fujimoto J Contemporary fixed prosthodontics. pp: 123.

4. Dumbrigue HB (2003) Composite indirect-direct method for fabricating multiple-unit provisional restorations. J Prosthet Dent 89(1): 86-88.

5. Rajashekhara BS, Keyur JM, Bhavna D, Poonacha KS (2012) Management of early loss of first permanent molar: A new technique. J Indian Pedod Prev Dent 30(4): 349-351.

6. Federick R (1975) The provisional fixed partial denture. J Prosthet Dent 34(5): 520-526. 


\section{Open Access Journal of Dental Sciences}

7. Miller SD (1983) The anterior fixed provisional restoration: a direct method. The Journal of Prosthetic Dentistry 50(4): 516-519.

8. Ante IH (1926) The fundamental principles of abutments. Mich State Dent Soc Bull 8: 14.

9. Malone W, Koth D, Cavazo E, Kaiser DA, Morgano SM, et al. Theory and Practice of Fixed Prosthodontics, $8^{\text {th }}$ (Edn.), St. Louis, Ishiyaku Euro-America pp: 71-87.
10. Rahul K, Archana D, Rahul G, Nandita B, Venu V, et al. (2016) To Splint or Not to Splint: The Current Status of Periodontal Splinting Journal of the International Academy of Periodontology 18(2): 45-56.

11. Short SG (1983) Immediate, provisional postextraction pontic placement. J Oral Maxillofac Surg 41(7): 475-477. 